\title{
Alternative Instructional Strategies in an IS Curriculum
}

\author{
Kevin R. Parker \\ Idaho State \\ University, \\ Pocatello, ID, USA
}

ParkerKR@isu.edu

\author{
Cynthia LeRouge \\ Saint Louis \\ University, \\ St. Louis, MO, USA
}

LeRougeC@slu.edu

\author{
Ken Trimmer \\ Idaho State \\ University, \\ Pocatello, ID, USA
}

\section{Abstract}

Systems Analysis and Design is a core component of an education in information systems. To appeal to a wider range of constituents and facilitate the learning process, the content of a traditional Systems Analysis and Design course has been supplemented with an alternative modeling approach. This paper presents an instructional design that incorporates a model from accounting literature (REA) with traditional Systems Analysis and Design methods in introducing the topic of data modeling. Detailed instructions for deriving data elements and relationships are presented. Feedback from students indicates increased satisfaction with the learning process and retention of material.

Keywords: Systems Analysis and Design, REA Modeling, Entity-Relationship Model, Database Model

\section{Introduction}

A Systems Analysis and Design (SAD) course is a core component of an information systems curriculum. This course typically contains a rather broad set of topics, ranging from planning strategies, project management, system analysis, and system design to related topics such as data modeling and object-oriented development methodologies. The breadth and depth of topics that are frequently covered in SAD make it a difficult course for not only students, but also for instructors.

One of our goals as educators is to build a solid and broad foundation of knowledge for our students. The better that we integrate long-accepted development strategies such as structured analysis and design with other business disciplines, the more solid the foundation becomes. By using the extremely adaptable Resources-Events-Agents (REA) model (McCarthy, 1982) to perform

Material published as part of this journal, either on-line or in print, is copyrighted by the publisher of the Journal of Information Technology Education. Permission to make digital or paper copy of part or all of these works for personal or classroom use is granted without fee provided that the copies are not made or distributed for profit or commercial advantage AND that copies 1) bear this notice in full and 2) give the full citation on the first page. It is permissible to abstract these works so long as credit is given. To copy in all other cases or to republish or to post on a server or to redistribute to lists requires specific permission and payment of a fee. Contact Editor@JITE.org to request redistribution permission. this integration with respect to data modeling, an SAD course can provide students with a per spective to extend familiar concepts, such as the duality of the accounting transaction. By explaining new material in terms of concepts already familiar to the student, both understanding and retention increase. Use of the REA model also links students' understanding of processes within an organizational context 
to widely accepted systems development strategies and database design.

Our approach to data modeling combines the concepts presented in traditional entity-relationship modeling (Chen, 1976) and the accounting information system (AIS) perspective of McCarthy's REA model (McCarthy, 1982). The combination of two approaches offers our students alternative perspectives for understanding the same problem. Because our SAD students are in the early stages of integrating a wide range of business concepts, our approach helps them utilize material learned elsewhere in the undergraduate business program with an integrated framework for business processes.

This manuscript provides a brief explanation of the systems analysis and design course, followed by a discussion of the REA model and its relationship with structured systems analysis and design methods. The following section presents the steps required to express an REA model as an entityrelationship diagram (ERD). The manuscript concludes with a discussion of the advantages of utilizing REA to assist in the teaching of core database analysis and design concepts, as well as reinforcing concepts typically found in the undergraduate curriculum.

\section{Systems Analysis and Design Course}

The IS 2002 Model Curriculum and Guidelines for Undergraduate Degree Programs in Information Systems (Davis, Feinstein, Gorgone, Longenecker, \& Valacich, 2003), a joint effort of the ACM, AIS, and AITP societies, provides a perspective on the overall content of an Information Systems program. One of the components of the guidelines is IS2002.7, Logical Analysis and Design. Scope and topics for the course are presented in the discussion as follows:

SCOPE: This course examines the system development and modification process. It emphasizes the factors for effective communication and integration with users and user systems. It encourages interpersonal skill development with clients, users, team members, and others associated with development, operation and maintenance of the system. Structured and object oriented analysis and design, use of modeling tools, adherence to methodological life cycle and project management standards.

TOPICS: Life cycle phases: requirements determination, logical design, physical design and implementation planning; interpersonal skills, interviewing, presentation skills; group dynamics; risk and feasibility analysis; group-based approaches: project management, joint application development (JAD), structured walkthroughs; structured versus object oriented methodologies; prototyping; database design; software package evaluation, acquisition, and integration; global and inter-organizational issues and system integration; professional code of ethics. (Davis et al., 2003, italics added)

The broad scope of the subject and numerous topics leaves little room for the instructor to introduce students to additional related topics, or to cover many of the topics in any depth. Our course contains the italicized topics as indicated above. We will refer to this course as Systems Analysis and Design, or SAD, throughout the remainder of this manuscript.

Within IS2002, the SAD course is a prerequisite to IS2002.8, Physical Design and Implementation with DBMS, as well as to IS2002.10, Project Management and Practice. Our specific curriculum is consistent with IS2002 in that our SAD course is a prerequisite/corequisite to Database Design, which is in turn a prerequisite for the Project Management and Practice, titled Advanced SAD in our curriculum.

Textbooks focusing on structured methods for the SAD course (Dennis \& Wixom, 2003; Hoffer, George, \& Valacich, 2005; Whitten, Bentley, \& Dittman, 2004), typically present the material in the planning, analysis, design, implementation sequence represented by the waterfall method. 
Such textbooks address both the scope and topics specified for IS2002.7 in the model curriculum. Our course follows this structure, but ends prior to the implementation phase.

In addition to conforming to IS2002, an SAD course may also need to serve multiple stakeholders. SAD may be a requirement or frequent elective for both the Computer Information Systems majors and Accounting majors within the College of Business. In addition, Computer Science majors from the College of Engineering may also be required to satisfactorily complete this course. The typical common denominator for SAD students is completion of an introductory programming course and junior standing at the university. Students from other majors who meet these requirements may also take the course, as may students enrolled in the Masters of Business Administration program.

Providing meaningful content to a broad set of students is a challenge. We report a new strategy utilized in our SAD course to help deliver the material effectively. Like many SAD courses, our course covers not only process modeling using tools like data flow diagrams, but also a brief introduction to data modeling using entity- relationship diagrams (ERDs). We introduce the students to a model utilized in Accounting Information Systems (AIS) for data modeling, the Resource, Event, Agent (REA) model proposed by McCarthy (1982, 2003).

\section{An Overview and Comparison of the REA Model vs. Existing Models in AIS and IS}

McCarthy $(1979,1982)$ proposed his seminal REA model as a means for an enterprise to capture the essence of economic exchanges between two parties. The REA model provides an alternative framework for modeling an organization's economic resources, economic events, economic agents, and their interrelationships. Resources are organization assets that are able to generate revenue. These can be tangible or intangible, but must be under the control of the organization. Resources do not include artifacts that can be generated from other primary data. Events are some phenomena that bring about changes in resources. Events provide a source of detailed data in this modeling approach. There are three classes of events: operating events, or activities that produce goods or provide services; information events, or activities associated with recording, maintaining, and reporting information; and decision/management events, or activities that lead to decisions being taken. The REA model addresses only operating events. Agents participate in events and can affect resources. They have discretionary power to use or dispose of resources. Agents can be an individual or organization inside or outside the organization that is capable of controlling economic resources and interacting with other economic agents. An extension of the REA model, known as the Resource-Event-Agent-Location (REAL) model adds location as a potential modeling element (Hollander, Denna, \& Cherrington, 2000). Location generally refers to the location of a resource or event.

REA models relationships between resources, events and agents. The REA model is deeply grounded in accounting and economic theory (Geerts \& McCarthy, 1997) and designed to provide information in order to answer five questions about an economic exchange (Denna \& McCarthy, 1987; Hollander, Denna, \& Cherrington, 1995): What happened? When did the exchange occur? What roles were played and by whom? What kind and how many resources were used? Where did the exchange occur?

Focusing on an economic event as a key business occurrence, McCarthy (1982) illustrates that the nature of an event is that an agent gives up a resource in receipt for another resource. For example, the script for a typical business transaction is as follows:

A customer (external agent) enters a retail establishment and shops for one or more items (resource). The customer selects these items and proceeds to pay for them (event) at a 
checkout stand (internal agent). The customer has exchanged currency for the basket of goods. Likewise, the retailer receives said currency and gives up said basket.

This perspective provides a starting point for investigating organizational events at a general level. In the preceding script, a change in scenario from a brick and mortar retail establishment to the World Wide Web does little to alter the essence of the economic event. A full-REA designed information system would emphasize the impact of recording the essential characteristics of business events and, with proper authority, makes the information available to information stakeholders both internal and external to an enterprise.

In its simplest form, the REA approach models the relationships in an economic exchange by recording the relationships between parties in terms of stock flows and control. Specifically, stock flows refer to the relationship between events and resources, and control refers to the relationship between events and agents. Figure 1 is adopted from McCarthy (1982) and displays the simplified REA model.

The generalizability of McCarthy's (1982) model is derived, in part, from the typical debit-credit model (DC) in accounting. The model represents the duality of the economic event presented to students in introductory accounting courses. Although the model was originally developed to provide a generalized framework for AIS in a shared database environment (McCarthy, 1982), it has evolved to be more comprehensive. Specifically, REA modeling has been discussed as a method for enterprise information systems to capture all business processes and events (Denna \& McCarthy, 1987). Individual business events represent the building blocks for economic events and are defined as "any strategically significant business activity management wants to plan, control, and/or evaluate” (Denna \& McCarthy, 1987, p.356).

REA modeling holds great potential for easy transference to an information systems curriculum that uses logical ERDs and physical models. The REA modeling technique is derived from the entity-relationship model introduced by Chen (1976), which itself was developed using Codd's (1970) relational model. Both of these models are frequently referenced in information systems courses. Because the symbolic component in the REA model is depicted as resources and agents (entities) associated via an event (relationship), the REA model is consistent with entityrelationship diagrams and, in fact, can be represented via a relational database management system. There are an increasing number of directed-REA databases (e.g., GENEVA ${ }^{2}$ from Price Waterhouse Consulting) that are being implemented (McCarthy, 1999).

In addition, McCarthy has extended the REA model to the enterprise, providing a Value-Chain perspective (Dunn, Cherrington, \& Hollander, 2005; McCarthy, 2003). The strength of this ontology flows from its enterprise perspective. Dunn et al. (2005) present a value chain viewpoint that categorizes overall processes into five broad processes: financing, acquisition/payment, payroll, conversion and sales/collection. By providing students with a perspective on grouping organizational events into logical categories, the REA model helps students focus on not only the interrelatedness of different processes, but also on how processes are consistent across organizations.

Full-REA modeling refers to tracking how resources are traced through enterprise-specific business functions, how business processes are interrelated and how they contribute to value, how specific tasks affect completion of economic events, and how business processes are controlled (Geerts, McCarthy, \& Rockwell, 1996).

This association of REA with both entities and processes flows readily into a presentation of structured methods. Multiple examples can be obtained for converting REA models into the entity-relationship model (Dunn et al., 2005). Focusing on common processes allows students to consider organizational idiosyncrasies as they decompose general processes into those specific to an organization. In addition, the REA model is touted as an ontology that frames organizational 


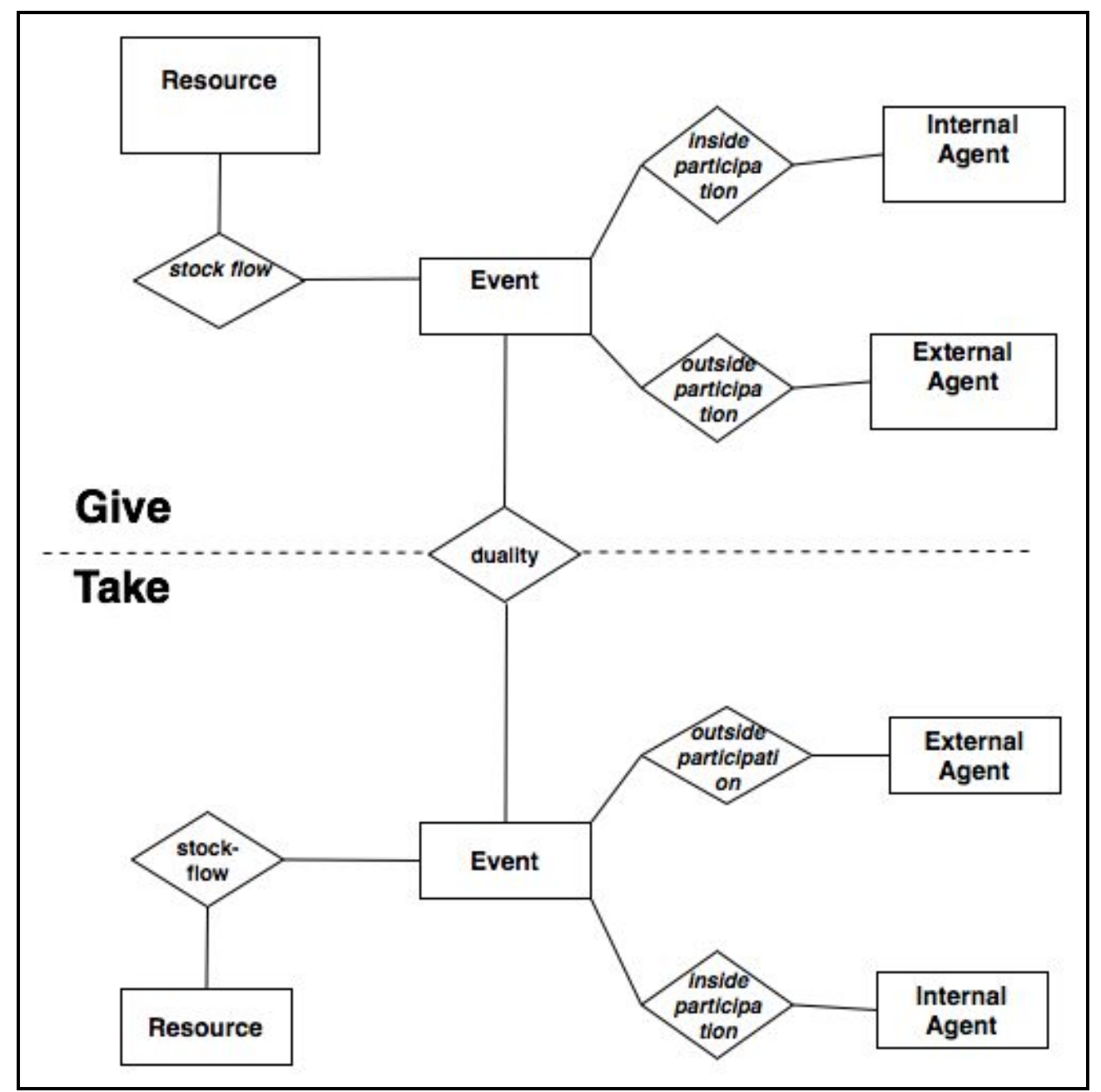

Figure 1. Generic REA Exchange Model Template (adapted from McCarthy, 1982)

information needs as a set of basic, enterprise components. The basic framework can readily generate an enterprise set of specifications that can be represented in a generalized REA model whose events can be further decomposed into specific tasks (Geerts \& McCarthy, 2001).

\section{Comparison of the REA Model to ER Models}

Although the REA approach is based on ER modeling, there are significant differences between the two methods. Three types of events may occur in an organization-operating events, information events and decision events. REA modeling is used most often with event-oriented accounting systems and therefore typically includes only operating events. In comparison, ER diagrams can capture all three types of events. While an ER diagram allows alignment between business processes and database tables, the REA model identifies areas for planning, evaluating and control of significant operating events. The REA model is more focused on business needs, and facilitates placement of internal controls. In general, details captured in an REA model are readily implemented. Table 1 provides further comparisons between the two modeling techniques. 
Table 1. Comparison of REA to ER Diagram

\begin{tabular}{|l|l|l|}
\hline Issue & REA & ER Diagram \\
\hline Symbols & $\begin{array}{l}\text { Entities rectangle, relationships } \\
\text { triangles }\end{array}$ & $\begin{array}{l}\text { Entities rectangle, relationships } \\
\text { triangles }\end{array}$ \\
\hline Cardinality/ Modality & Not expressed in diagram & Shown in diagram \\
\hline $\begin{array}{l}\text { Type of system typically mod- } \\
\text { eled }\end{array}$ & Event-oriented & Traditional event -based \\
\hline $\begin{array}{l}\text { Can be represented via rela- } \\
\text { tional DBMS }\end{array}$ & Yes & Yes \\
\hline Presentation of Events & Shown as entities & Shown as relationship \\
\hline Types of events captured & Operating only & $\begin{array}{l}\text { Operating, decision, and infor- } \\
\text { mation events }\end{array}$ \\
\hline Focus & Business needs and planning & Database structure \\
\hline Controls & $\begin{array}{l}\text { Facilitates placement on inter- } \\
\text { nal controls }\end{array}$ & $\begin{array}{l}\text { Controls are addressed else- } \\
\text { where in system planning }\end{array}$ \\
\hline Development process & Semantic flow & $\begin{array}{l}\text { Somewhat randomization and } \\
\text { database normalization }\end{array}$ \\
\hline Identification of relationships & $\begin{array}{l}\text { Semantic, based upon pre- } \\
\text { identified templates }\end{array}$ & Sometimes arbitrary \\
\hline
\end{tabular}

\section{Using REA in the IS Educational Process}

The REA model affords students intellectual control by imposing conceptual structure and by minimizing the initial focus to a minimal set of necessary organizational elements. In essence, the student focuses on one, conceptually unified part of a data model (called an entity set) at a time. The parts are ultimately linked to form a comprehensive model. Decomposing complex data models to allow focus on relevant conceptual sections is common in practice. For example, it is rare to consider the complete data model for an entire enterprise resource planning system; rather it is more common to consider components individually.

The REA model lends itself to adaptation, and can be revised to address further complexity (Weber, 1986). Because of its broad conceptual nature and definitions, REA is a highly rule-based, yet flexible approach. It allows students to build their mental models and achieve modeling tasks in an efficient and effective manner as they link high-level conceptual representations of business goals to models generally accepted for both logical and physical modeling. Dunn and Grabski (1997) provide empirical support for REA's superiority in terms of accuracy of task and user satisfaction. Studies indicate REA provides students with improved conceptual model understanding, and a more exact understanding of the infrastructure for accounting systems (Poels, Maes, Gailly, \& Paemeleire, 2004). REA also provides a framework for the unification of Accounting Information Systems curriculum, and is utilized both in graduate and undergraduate programs (McCarthy, 2003).

Aside from potential gains in teaching effectiveness and efficiency, the REA approach also has the benefit of being consistent with a general undergraduate business curriculum emphasizing strategy. REA can also serve as a method to assist in identifying elements on the Value Chain (Porter \& Millar, 1985) and converting them into readily understood models, such as the ERD (Hollander et al., 2000). Because the REA model initially focuses on economic events, it provides 
competition for the purely economic and incumbent debit-credit model. IS curricula are challenged with equipping students with the ability to view technology from a strategic perspective. In business contexts, a strategic approach to process modeling contributes to the on-going support for necessary functions and potential competitive advantage.

In addition, the REA model incorporates contextual teaching and learning. Because modeling is presented in terms of concepts already familiar to the student from previous courses, e.g., the duality of the accounting transaction, students can immediately see the relevance of their prior knowledge and are more likely to understand the concepts because they can be related to something familiar (Crawford, 2001). Contextual learning theory asserts that learning occurs when students process new information or knowledge in such a way that it makes sense to them in their own frames of reference. This approach assumes that the mind naturally seeks meaning in context - that is, in relation to the person's current environment—and that it does so by searching for relationships that make sense and appear useful (Texas Collaborative for Teaching Excellence, 2002). Should an instructor have a set of students not familiar with general business concepts, such as many of our computer science students, the model can readily be converted into a script relating occurrences that all students experience, for example purchasing a book at the campus bookstore, a local retailer, or on-line. Even students in non-business majors have experience with basic economic transactions (e.g. making purchases); and as such, even those without explicit exposure to accounting theory have had implicit exposure to the concepts upon which REA is based, allowing them to relate the model to a familiar activity. Thus, the REA model can be utilized to help construct the student's day-to-day experiences into a more structured framework.

Finally, the REA model has been extended into a broader set of information systems analysis and design applications. Haugen and McCarthy (2000) propose a framework for standardizing XML by using the REA model. The model has also been related to object-oriented knowledge-based systems (Geerts \& McCarthy, 1999), development of enterprise systems (David, Gerard, \& McCarthy, 2002; Haugen \& McCarthy, 2000), and design science (David et al., 2002). The authors currently are exploring the application of REA to process modeling teaching methods.

\section{Teaching the REA Approach to Drawing ERDs}

The steps for identifying elements in the REA approach are similar to the steps that are followed when developing an ERD. The designer must identify entity sets, which include the various resources and agents of business events that the model captures, as well as the relevant relationships between the entities. One advantage of this approach is that it incorporates key nonfinancial/noneconomic data that may be overlooked in other models. Tables 2-6 show the instructional steps involved in REA modeling.

\section{Phase 1}

Developing the REA model requires that significant events be identified. Those events should be classified as operating events, information events, or decision/management events. Only the operating events will be included in the model. Operating events are those that support the strategic objectives of the organization and about which information must be gathered. We begin by having students identify events a specific organization would like to capture. Guidance given by the instructor at this first stage includes defining the goals and business rules of the organization, as well as processes the information system should support. 
Table 2. REA Instructional Steps 1-2 (Phase 1)

\begin{tabular}{|c|c|c|c|}
\hline \multicolumn{4}{|c|}{ Phase 1 - Identify the Entity Set } \\
\hline No. & Step & $\begin{array}{ll} & \text { Representative Prompt Questions }\end{array}$ & $\begin{array}{l}\text { Example- Customer } \\
\text { Purchases Inven- } \\
\text { tory Item by Paying } \\
\text { Cash }\end{array}$ \\
\hline 1 & Identify events & $\begin{array}{l}\text { What events occur during the course } \\
\text { of business? } \\
\text { - What are the operational goals of the } \\
\text { business? } \\
\text { - What processes should or could the } \\
\text { information system support within } \\
\text { the organization? }\end{array}$ & $\begin{array}{ll}\text { - } & \text { Sale } \\
\text { - } & \text { Cash Receipt }\end{array}$ \\
\hline 2 & $\begin{array}{l}\text { Create a story about } \\
\text { each event. Select } \\
\text { one event from } \\
\text { which to develop an } \\
\text { entity set. }\end{array}$ & $\begin{array}{l}\text { Identify Economic Resources - What } \\
\text { resources are necessary for the event } \\
\text { to occur? } \\
\text { Identify Economic Agents - What } \\
\text { internal actor(s) are necessary for the } \\
\text { event to occur? What external ac- } \\
\text { tor(s) are necessary for the event to } \\
\text { occur? } \\
\text { Does the business actually want to } \\
\text { record information about the candi- } \\
\text { date entities? }\end{array}$ & \begin{tabular}{ll}
\multicolumn{2}{l}{ Sale (Give) } \\
- & Resource - Inventory \\
- & Internal Agent - \\
& Salesperson \\
- & External Agent - \\
& Customer \\
& \\
Cash Receipt (Take) \\
- $\quad$ Resource - Inventory \\
- $\quad$ Internal Agent - \\
$\quad$ Cashier \\
- \\
$\quad$ External Agent - \\
Customer
\end{tabular} \\
\hline
\end{tabular}

Students are next instructed to create a narrative about each event in which the "players" (internal agents, external agents) and resources are identified. REA is an iterative process. Each iteration focuses on a single event only, for which an entity set is developed. Each resulting entity set represents a logical model segment, which can be likened to an "event" view of the data model. Each iteration is restricted to a single event in order to facilitate intellectual control. The comprehensive integration of the entity sets (i.e., model segments) begins only after all entity sets have been specified.

This approach gives the students an opportunity to focus on and visualize each aspect of the event of interest to create a comprehensive picture. In developing the narrative, the students should identify associated main components, namely the "players" and resources necessary for the enactment of the event.

After all resources and agents associated with an event have been identified, the instructor should explain that each one is an entity and represents a unit to be modeled. Collectively, the group represents a related set of entities (referred to as an entity set in this paper). 
Table 3. REA Instructional Steps 3-4 (Phase 2)

\begin{tabular}{|c|c|c|c|}
\hline \multicolumn{4}{|c|}{ Phase 2 - Identify Attributes for the Entity Set } \\
\hline No. & Step & $\begin{array}{l}\text { Representative Prompt Ques- } \\
\text { tions }\end{array}$ & $\begin{array}{l}\text { Example- Customer } \\
\text { Purchases Inventory } \\
\text { Item by Paying Cash }\end{array}$ \\
\hline 3 & $\begin{array}{l}\text { Identify story de- } \\
\text { tails (working } \\
\text { through one } \\
\text { event) }\end{array}$ & $\begin{array}{l}\text { What details about the event, } \\
\text { each resource, and each agent } \\
\text { would be relevant to the organi- } \\
\text { zation's business process and/or } \\
\text { strategy? } \\
\text { What information would help } \\
\text { the organization determine } \\
\text { trends related to resources, } \\
\text { events, and agents? }\end{array}$ & $\begin{array}{ll}\text { Customer Entity } \\
\text { - } & \text { Cust_F_Name } \\
\text { - } & \text { Cust_L_Name } \\
\text { - } & \text { Cust_Street } \\
\text { - } & \text { Cust_Street2 } \\
\text { - } & \text { Cust_Zip } \\
\text { - } & \text { Cust_City } \\
\text { - } & \text { Cust_State } \\
\text { - } & \text { Cust_Zip } \\
\text { - } & \text { Cust_Phone } \\
\text { - } & \text { Cust_How_Heard_H } \\
& \text { About_Us } \\
\text { - } & \text { Cust_Year_Birth } \\
\text { - } & \text { Etc. } \\
\end{array}$ \\
\hline 4 & $\begin{array}{l}\text { The rest of the } \\
\text { story }\end{array}$ & $\begin{array}{l}\text { Do the attributes identified } \\
\text { really complete the story to the } \\
\text { level of detail desired by the or- } \\
\text { ganization? } \\
\text { Are there any nuances that oc- } \\
\text { cur outside of the norm that } \\
\text { need to be added? } \\
\text { Do we have any dependent, } \\
\text { subtype of supertype entities? }\end{array}$ & $\begin{array}{ll}\text { Customer Entity } \\
\text { - } & \text { Employee subtype } \\
\text { exists } \\
\text { - } \\
\text { Employees are eligi- } \\
\text { ble for a discount on } \\
\text { inventory items. } \\
\text { Hence, additional at- } \\
\text { tributes needed: } \\
\text { - Cust_Employee } \\
\text { (Y/N) } \\
\text { - Cust_Empl_Discount }\end{array}$ \\
\hline
\end{tabular}

\section{Phase 2}

After students identify the component entities within an entity set, they can begin to determine the relevant business details associated with each component entity. In essence, the student is defining each event, resource and agent within the context.

Students should articulate the attributes (i.e. details) within the narrative of the business event to facilitate visualization. Relevance is guided by the context of the story (i.e., business goals and operational process). Hence, the attributes should be highly specific to the organization being modeled. Organizations do not necessarily share the same views as to what details need to be modeled. The instructor can highlight the fact that divergent views of relevant data among organizations is both a driving factor in the adoption of Enterprise Resource Planning Systems (ERPs), as well as the primary cause of failure in adopting ERPs. Either the ERP must be modified to comply with the specific organizational data and process needs, or the organization must adapt its needs to the ERP system.

Now that the resources and agents have been identified, the instructor should ask the students to reconstruct the narrative about the event using the key components (attributes) they have identified and details (attributes) about those components to insure they have expressed a complete and relevant representation of the event. Students should critically analyze whether anything has been omitted from a current needs as well as a future needs perspective. This helps reinforce the benefit of iteration in the overall systems development process. 
Following this clarification of the model, the instructor should describe the concepts of dependent, subtype and supertype entities, and/or the generalization concepts of superclass and subclass used in the Unified Modeling Language (UML) (Dennis, Wixom, \& Tegarden. 2002). The students' mental models should be complete enough to determine if any of those special entities apply to the story and if so, where to put them. This step can also be used to begin to build the links between the modeling process and the eventual implementation of the system. Many students are already familiar with the concept of classes from object-oriented programming classes. The ongoing reinforcement of the link between models and applications not only guides students, but also reduces the frustration that they might experience in learning the complex analysis process.

Table 4. REA Instructional Steps 5-6 (Phase 3)

\begin{tabular}{|c|c|c|c|}
\hline \multicolumn{4}{|c|}{ Phase 3 - Identify Relationships among Entities in Set } \\
\hline No. & Step & - $\quad$ Representative Prompt Questions & $\begin{array}{l}\text { Example- Customer } \\
\text { Purchases Inventory } \\
\text { Item by Paying Cash }\end{array}$ \\
\hline 5 & $\begin{array}{l}\text { Place/Draw Event } \\
\text { Entity in Center }\end{array}$ & $\bullet$ & $\begin{array}{l}\text { Sale would be positioned } \\
\text { in center of diagram. }\end{array}$ \\
\hline 6 & $\begin{array}{l}\text { Connecting the enti- } \\
\text { ties through REA } \\
\text { templates }\end{array}$ & $\begin{array}{l}\text { Do we have stock flow relationships } \\
\text { (+/- economic resources)? } \\
\text { Do we have duality relationships } \\
\text { (associate dual parts of a single eco- } \\
\text { nomic exchange)? } \\
\text { Do we have control relationships } \\
\text { (ternary connection among an inside } \\
\text { agent, external agent, \& economic } \\
\text { event)? } \\
\text { Do we have a responsibility relation- } \\
\text { ship (higher level units control and } \\
\text { are accountable for the activities of } \\
\text { subordinate level)? }\end{array}$ & $\begin{array}{l}\text { Stock flow relationships: } \\
\text { - } \quad \text { Sale and Payment } \\
\text { - } \quad \text { Sale and Inventory } \\
\text { - } \quad \text { Sale and Customer } \\
\text { - } \quad \text { Cash receipt } \\
\text { Duality relationships } \\
\text { - } \quad \text { Sale and Cash Re- } \\
\quad \text { ceipt } \\
\text { See Figure } 2 \text { for repre- } \\
\text { sentative diagram. }\end{array}$ \\
\hline
\end{tabular}

\section{Phase 3}

The links between resources, events and agents must next be identified, and the associations or cardinalities of all entity relationships must be recorded. Dunn and McCarthy (1997) describe the four different types of relationships that can be expressed in the REA model:

- Stock-flow relationships denote events that increase or decrease economic resources.

- Duality relationships associate the dual parts of a single economic exchange.

- Control relationships are ternary connections between an inside agent, an outside agent and an economic event.

- Responsibility relationships indicate that higher-level units control and are accountable for the activities of subordinates.

Each of these relationships must be fully considered in any semantic diagram analysis. Figure 2 displays the stock-flow relationships and provides a general REA template that instructors can use to teach the model.

Relationships between these items/entities and other entities, their corresponding rules, cardinalities, and state changes can be better understood once all of the economic events and their attributes have been identified and defined. What is critical here is to have the students determine whether or not the entities need to be broken down further, or if the relationship is a form of an 
event to be modeled as an association. The student must also review the attributes of all entities to insure no anomalies exist.

A discussion of anomalies can be used to introduce the students to the concepts of keys and normalization. Discussing the requirement that each entity must have a unique identifier or key can lead to further discussion of the importance of events, which contain details (foreign keys) corresponding to the relationship with resources and agents. This can lead the instructor and student into the important concepts of keys, foreign keys and normalization. At this point, the students are ready to draw the model in basic REA, then ERD, form.



Figure 2. REA Template Applied to Example to Create ER Diagram 


\begin{tabular}{|c|c|c|c|}
\hline \multicolumn{4}{|c|}{ Table 5. REA Instructional Steps 7-11 (Phase 4) } \\
\hline \multicolumn{4}{|c|}{ Phase 4 - Refine Diagram } \\
\hline No. & Step & - $\quad$ Representative Prompt Questions & $\begin{array}{l}\text { Example- Customer } \\
\text { Purchases Inventory } \\
\text { Item by Paying Cash }\end{array}$ \\
\hline 7 & Validate Entities & $\begin{array}{l}\text { Have any entities been identified that } \\
\text { we do not want to track information } \\
\text { about? } \\
\text { Do all entities have more than one } \\
\text { instance? }\end{array}$ & $\begin{array}{l}\text { If the organization does } \\
\text { not keep track of sales- } \\
\text { people associated with a } \\
\text { sale, this entity may be } \\
\text { eliminated. }\end{array}$ \\
\hline 8 & Merge Entities & $\begin{array}{l}\quad \text { Consider merging entities with a } \\
\text { one-to-one relationship. }\end{array}$ & $\begin{array}{l}\text { Cash may be merged } \\
\text { into cash receipt. }\end{array}$ \\
\hline 9 & $\begin{array}{l}\text { Add normalization } \\
\text { entities }\end{array}$ & $\begin{array}{l}\text { - Are there any attributes that may } \\
\text { contain more than one value? }\end{array}$ & $\begin{array}{l}\text { Does the customer have } \\
\text { multiple phone num- } \\
\text { bers? Hence, a new en- } \\
\text { tity customer phone is } \\
\text { required. }\end{array}$ \\
\hline 10 & Add event triggers & $\begin{array}{l}\text { Does the entity list include represen- } \\
\text { tation of trigger events? }\end{array}$ & $\begin{array}{l}\text { Are sales initiated by } \\
\text { calls to customers? If so, } \\
\text { a call entity might be } \\
\text { needed. }\end{array}$ \\
\hline 11 & $\begin{array}{l}\text { Create additional } \\
\text { entity sets }\end{array}$ & $\begin{array}{l}\text { Work through steps 2-10 until entity } \\
\text { sets for all identified events have } \\
\text { been specified }\end{array}$ & \\
\hline
\end{tabular}

\section{Phase 4}

In this phase, students draw the model by placing the event in the center and working out. The instructor should note that typically the various resources and agents associated with an event are connected indirectly through the event, rather than directly to each other. It is the event that brings these agents and resources together.

This decomposition process can address adapting the model to a specific domain. In addition, students can be introduced to further adaptability of the REA model as it relates to non-economic events that can be improved via normalization (Weber, 1986).

If the instructor wants to impart a more complex and thorough understanding of the modeling process, the generic REA model can be complemented by a template that can be extended in the same fashion as Hollander et al. (2000). This modification adds business objectives and event triggers to the basic set of items addressed in the REA. A similar approach can be seen in the events table, an analysis technique proposed for general systems analysis (Satzinger, Jackson, \& Burd, 2000). The events table is a matrix that associates triggers, sources, activities, responses and destinations for each individual event, whether being initiated externally, temporally, or triggered by a state change. Satzinger et al. (2000) utilize the events table as the input source for different analysis and design methodologies, including structured, information engineering and object-oriented. 
Table 6. REA Instructional Steps 12-13 (Phase 5)

\begin{tabular}{|l|l|l|l|}
\hline \multicolumn{3}{|c|}{ Phase 5 - Link the Various Entity Sets into a Comprehensive Model } \\
\hline No. & Step & Representative Prompt Questions & $\begin{array}{l}\text { Example- Customer } \\
\text { Purchases Inventory } \\
\text { Item by Paying Cash }\end{array}$ \\
\hline 12 & $\begin{array}{l}\text { Create unified model } \\
\text { that encompasses all } \\
\text { business operations } \\
\text { (i.e. all entity sets are } \\
\text { represented) }\end{array}$ & $\begin{array}{l}\text { Are there multiple names used } \\
\text { across entity sets to represent the } \\
\text { same entity? }\end{array}$ & $\begin{array}{l}\text { Business Process Issue: } \\
\text { May determine payment } \\
\text { entity is needed to ac- } \\
\text { commodate on credit, } \\
\text { cash, and credit card } \\
\text { sales. }\end{array}$ \\
\hline 13 & $\begin{array}{l}\text { Are there multiple names used } \\
\text { across entity sets to represent the } \\
\text { same attribute? } \\
\text { Are attributes associated with just } \\
\text { one entity in the comprehensive } \\
\text { model? } \\
\text { Does the collective list of attributes } \\
\text { for each entity include all attributes } \\
\text { identified for the entity for each data } \\
\text { set? } \\
\text { Is the aggregated model logical and } \\
\text { consistent with business processes } \\
\text { and strategies? }\end{array}$ & \\
\hline
\end{tabular}

\section{Phase 5}

The students will keep developing entity sets, defining attributes and drawing conceptually complete portions of the model until all business goals have been addressed. Most introductory models will involve few entity sets. However, introducing students to this iteration process should provide structural guidance in how to approach situations that require more complex models.

The final step is to link individual component models into one unified model that encompasses all business operations. Students may have to resolve some inconsistencies. However, addressing these inconsistencies may reveal valuable information about inconsistencies that actually exist in the organizational context and deserve attention.

The students should leave this module with the understanding that the REA model is high-level and very conceptual. By focusing on the model, the student can gain an understanding as to how the big pieces of the systems puzzle fit together. Linking the REA model to modeling techniques that are supported by industrial-strength software applications, like computer-aided software engineering (CASE) tools, and that eventually lead to quality applications, also provides relevance for the comprehension of the difficult conceptualization of an organization and its processes.

Following the creation and validation of the ERDs and process models, the student can then proceed to system design and implementation. While it is beyond the scope of this modeling discussion, strategies for moving from analysis to design are proposed by numerous authors. For example, Dennis and Wixom (2003) propose a five-step approach that includes relating model components to physical tables, human-computer interaction, system level issues, and updating both the data flow elements and metadata. A similar strategy is presented by Whitten et al., (2004) wherein the analytical models are represented in application architecture, system database and interface, package specifications, and an update of the project plan. Should the analyst choose to 
utilize other strategies to assist in the conversion of conceptual models to physical ones, such as use cases (Dennis \& Wixom, 2003), object oriented models such as UML (Whitten et al., 2004), rapid application development such as prototyping (Marakas, 2006), or other combinations of methods, ERDs derived from REA analysis can be converted to a physical representation.

\section{Experiential Assessment}

Analysis of student feedback and performance indicates that students both favor the REA approach over a "classification" approach and that the REA approach may facilitate student ability to identify appropriate entities and determine appropriate relationships between entities.

Student preference for REA was indicated in an informal student survey associated with an introductory undergraduate systems analysis and design course in Spring 2003. Both the REA approach (dubbed the "top-down" approach for the purposes of this class) and the more traditional, "bottom-up, classification" approach were used in the process of introducing students to data modeling. Students were asked to complete a course feedback form to enable the instructor to make future course adjustments. One question asked them to state their preference for the classification or REA (top-down) approach to identify entities and relationships in data modeling. Of the 21 students responding to this question, 18 students (86\%) responded that they preferred the REA approach. Table 7 provides a listing of the adjectives used by students to describe each approach. Although they are listed a single time only in the table, it is notable that many adjectives were repeated by multiple students.

Table 7. REA Preference Student Qualifiers

\begin{tabular}{|l|l|}
\hline REA (top-down) approach & Classification (bottom-up) approach \\
\hline “more organized” & "haphazard" \\
\hline “helpful” & \\
\hline “points out all of the important elements" & \\
\hline “very useful” & \\
\hline "helps to get the diagram started” & \\
\hline "ERDs work out o.k. with the REA method” & \\
\hline “provides more up-front knowledge" & \\
\hline “good method" & \\
\hline
\end{tabular}

Informal analysis of student performance between the two methods was done by asking students to declare the approach they took to complete a data modeling homework assignment (the second data modeling assignment in the course) and comparing the performance of the two groups. Only 14 of the 24 students who completed the assignment indicated the method used. The majority (10 students) of the 14 students indicated that they used the REA approach. Performance of those students who indicated a method was assessed using a detailed evaluation criteria (see Table 8) for entity-relationship diagrams adapted from past research (Gjestland, 2000). This evaluation criterion was available to all students as part of their course materials in order to facilitate understanding of modeling issues. The indications of distinctions between the students using the REA 
Table 8. Distinctive Criterion Items in Assessing Entity-Relationship Modeling Performance

\begin{tabular}{|l|l|}
\hline Criterion & Criterion Description \\
\hline Non-noun entities. & $\begin{array}{l}\text { An entity that is not named with a noun. Incorrect exam- } \\
\text { ples include "Record Price” or "Track Purchase". }\end{array}$ \\
\hline Missing entities. & One of the required entities is missing. \\
\hline Incorrect extra entities. & $\begin{array}{l}\text { Additional entities are specified that are not in the ap- } \\
\text { propriate list of entities. }\end{array}$ \\
\hline $\begin{array}{l}\text { Entities that should be attributes or rela- } \\
\text { tionships. }\end{array}$ & $\begin{array}{l}\text { An entity that should be an attribute (like Name) or a } \\
\text { relationship. }\end{array}$ \\
\hline Missing relationships. & One or more of the required relationships is not shown. \\
\hline Incorrect extra relationships. & $\begin{array}{l}\text { Relationships are drawn between entities that are incor- } \\
\text { rect. Incorrect extra relationships may exist for entities } \\
\text { not specified in the solution set. }\end{array}$ \\
\hline
\end{tabular}

method and the students using the "classification" approach seemed most evident in assessing performance related to the evaluation items.

The students using the "classification" approach tended to have problems completely satisfying the criterion requirements stated above, namely in identifying all and only appropriate entities and in modeling appropriate relationships. Given that this assessment was not within the realm of a controlled empirical investigation and the disparity in the number of self-selecting students, it is quite possible that other confounding factors could have accounted for these differences in performance. As such, the tendencies stated should be interpreted as commentary on observation.

The indications of student preference and performance discussed provide suggestions that an REA approach to introducing entity-relationship diagramming may have some merit, and empirical investigation comparing these two approaches may prove enlightening.

\section{Conclusions}

Modeling ERDs is an important IS skill taught in an IS curriculum at most universities. However, as this paper points out, the current method of teaching ERD modeling is inefficient and ineffective for today's students and may not provide the strategic perspective valued in industry. Furthermore, this paper provides some preliminary evidence of a preference for the REA method by undergraduate students.

The REA model is a highly conceptual tool for helping students think about entities in an improved process, and enjoys widespread use in Accounting Information Systems (AIS) classes across the nation. The model provides a framework for understanding business processes, and helps to direct the modeler's initial focus toward understanding the processes. The ability to represent parts of the model as scripts or narratives helps enable the student to see both the general and specific issues in a given situation. The model as presented in our course is linked to value chain concepts, as well as both data and process modeling. We believe that this perspective is beneficial in linking business and technical concepts, thereby enhancing our students' future career performance.

REA provides a means to semantically address other forms of modeling, and the authors are currently exploring these issues in instructional settings. Utilizing a conceptual tool such as REA for deriving data requirements and relationships to address other models and methodologies should 
prove to be a fruitful endeavor, as we constantly strive for better ways to represent the real world conceptually. REA's potential to supplement or reinforce such widely used modeling techniques as data flow diagrams, unified modeling language (UML), the CRC (class responsibility collaborator) modeling process (Ambler, 1998), and other models such as the Reference Model of Open Distributed Processing and General Relationship Model (Kilov, 2002) warrant further investigation and will be the subject of future research. Alternative methodologies such as rapid application development, iterative prototyping, and agile methods may also be complemented by REA, further extending the applicability of the conceptual REA in systems analysis and design endeavors. For example, agile methods have at their core the goal of efficiency and contextual system understanding among all persons on the project team, and REA can be used to improve communication between the analyst/designer and users. Additional future REA research will focus on addressing these alternatives in an instructional setting.

\section{References}

Ambler, S.W. (1998). CRC Modeling - Bridging the communication gap between developers and users. Ambysoft Inc. Retrieved January 12, 2005, from http://www.ambysoft.com/crcModeling.PDF

Chen, P.P. (1976). The Entity-Relationship Model - Toward a unified view of data. ACM Transactions on Database Systems, 1 (1), 9-36.

Codd, E.F. (1970). A relational model of data for large shared data banks. Communications of the ACM, 13 (6), 377-387.

Crawford, M. (2001). Contextual teaching and learning: Strategies for creating constructivist classrooms. Connections 11 (6), 1-2, 6. Retrieved November 15, 2004, from http://www.cord.org/pdf/LayoutforWeb.pdf

David, J.S., Gerard, G.J., \& McCarthy, W.E. (2002). Design science: An REA perspective on the future of AIS. In V. Arnold \& S. Sutton (Eds.), Research Accounting as an Information Systems Discipline (pp. 35-63). Sarasota, FL: American Accounting Association.

Davis, G.B., Feinstein, D.L., Gorgone, J.T., Longenecker, H.E. Jr., \& Valacich, J.S. (2003). IS 2002 model curriculum and guidelines for undergraduate degree programs in information systems. Communications of the AIS, 11 (1), 1-63.

Denna, E.L., \& McCarthy, W.E. (1987). An events accounting foundation for DSS implementation. In C.W. Holsapple \& A.B. Whinston (Eds.), Decision support systems: Theory and application (pp. 239263). Berlin: Springer-Verlag.

Dennis, A., \& Wixom, B.H. (2003). Systems analysis and design ( $2^{\text {nd }}$ ed.). New York, NY: John Wiley \& Sons.

Dennis, A., Wixom, B., \& Tegarden, D. (2002). Systems analysis and design: An object-oriented approach with UML. New York, NY: John Wiley \& Sons.

Dunn, C., Cherrington, A.O., \& Hollander, A.S. (2005). Enterprise information systems: A pattern-based approach ( ${ }^{\text {rd }}$ ed.). Boston: McGraw-Hill/Irwin.

Dunn, C., \& Grabski, S.V. (1997). Cognitive fit and a comparison of two accounting models. Proceedings of the Annual Meeting of the American Accounting Association, Dallas, TX.

Dunn, C., \& McCarthy, W.E. (1997). The REA accounting model: Intellectual heritage and prospects for progress. Journal of Information Systems, (Spring), 31-51.

Geerts, G.L., McCarthy, W.E., \& Rockwell, S.R. (1996). Automated integration of enterprise accounting models throughout the systems development life cycle. Intelligent Systems in Accounting, Finance, and Management, 5 (3), 113-128. 
Geerts, G.L., \& McCarthy, W.E. (1997). Modeling business enterprises as value-added process hierarchies with resource-event-agent object templates. In J. Sutherland \& D. Patel (Eds.), Business object design and implementation (pp. 94-113). London: Springer-Verlag.

Geerts, G.L., \& McCarthy, W.E. (1999). An accounting object infrastructure for knowledge-based enterprise models. IEEE Intelligent Systems \&Their Applications, (July/August), 89-94.

Geerts, G.L., \& McCarthy, W.E. (2001). Using object templates from the REA accounting model to engineer business processes and tasks. The Review of Business Information Systems, 5 (4), 89-108.

Gjestland, C. (2000). Applying cognitive skill acquisition theory to the training needs assessment of information technology professionals: An initial study (Doctoral dissertation, University of South Florida, 2000).

Haugen, R., \& McCarthy, W.E. (2000, October). REA, a semantic model for Internet supply chain collaboration. Paper presented at the Business Objects and Component Design and Implementation Workshop VI: Enterprise Application Integration, ACM Conference on Object-Oriented Programming, Systems, Languages, and Applications. Retrieved December 21, 2004, from http://jeffsutherland.org/oopsla2000/mccarthy/mccarthy.htm

Hoffer, J.A., George, J.F., \& Valacich, J.S. (2005). Modern systems analysis and design (4 ${ }^{\text {th }}$ ed.). Upper Saddle River, NJ: Prentice-Hall.

Hollander, A.S., Denna, E.L., \& Cherrington, J.O. (1995). Accounting, information technology, and business solutions. Chicago, IL: Richard D. Irwin.

Hollander, A S., Denna, E.L., \& Cherrington, J.O. (2000). Accounting, information technology, and business solutions ( $2^{\text {nd }}$ ed.). Boston, MA: McGraw-Hill/Irwin.

Kilov, H. (2002). Business models. Upper Saddle River, NJ: Prentice-Hall.

Marakas, G.M. (2006). Systems analysis and design: An active approach. Boston, MA: McGrawHill/Irwin.

McCarthy, W.E. (1979). An entity-relationship view of accounting models. The Accounting Review, (October), 667-686.

McCarthy, W.E. (1982). The REA accounting model: A generalized framework for accounting systems in a shared data environment. The Accounting Review, (July), 554-578.

McCarthy, W.E. (1999). Semantic modeling in accounting education, practice, and research: Some progress and impediments. In P. P. Chen, J. Akoka, H. Kangassalo, \& B. Thalheim (Eds.), Conceptual modeling: Current issues and future directions (pp. 144-153). Berlin: Springer Verlag.

McCarthy, W.E. (2003). The REA modeling approach to teaching accounting information systems. Issues in Accounting Education, (November), 427-441.

Poels, G., Maes, A., Gailly, F., \& Paemeleire, R. (2004). User Comprehension of Accounting Information Structures: An empirical Test of the REA Model. Working Paper, Ghent University, July. Retrieved November 18, 2004, from http://www.feb.ugent.be/fac/research/WP/Papers/wp_04_254.pdf

Porter, M., \& Millar, V. (1985). How information gives you competitive advantage. Harvard Business Review 63 (July-August), 149-160.

Satzinger, J.W., Jackson, R.B., \& Burd, S.D. (2000). Systems analysis and design in a changing world. Cambridge, MA: Course Technology.

Texas Collaborative for Teaching Excellence. (2002). What is contextual teaching and learning? Retrieved November 16, 2004, from http://www.texascollaborative.org/WhatIsCTL.htm

Weber, R. (1986). Data models research in accounting: An evaluation of wholesale distribution software. The Accounting Review, (July), 498-518.

Whitten, J.L., Bentley, L.D., \& Dittman, K. (2004). Systems analysis and design methods (6 ${ }^{\text {th }}$ ed.). Boston, MA: McGraw-Hill/Irwin. 


\section{Biographies}

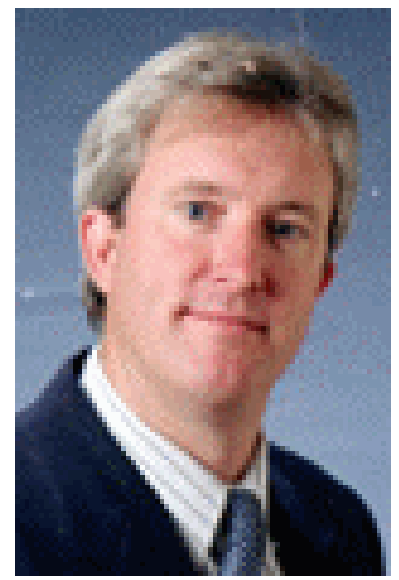

Kevin R. Parker is a Professor of Computer Information Systems at Idaho State University. He has taught classes in both computer science and information systems over the course of his thirteen years in academia. Dr. Parker's research interests include e-commerce marketing, competitive intelligence, information filtering, knowledge management, the Semantic Web, and extreme programming. He has published several papers in these areas including publications in the International Journal of Internet and Enterprise Management, Journal of Information Systems Education, Journal of Issues in Informing Science and Information Technology, European Journal of Marketing, and Marketing Intelligence and Planning as well as refereed chapters in researchbased books. Dr. Parker's teaching interests include web development technologies, programming languages, data structures, and database management systems. Dr. Parker holds an MS in Computer Science and a Ph.D. in Management Information Systems from Texas Tech University.

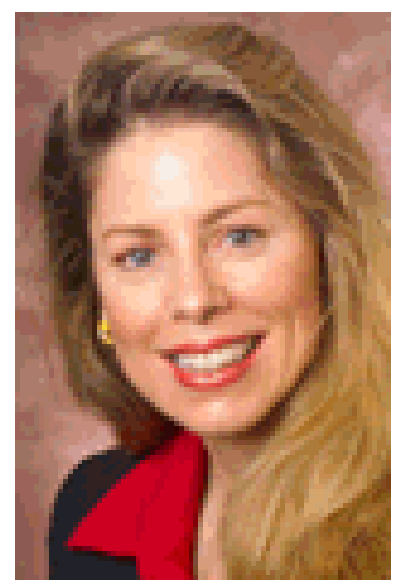

Cynthia LeRouge is an Assistant Professor at St. Louis University. Her current research interests relate to healthcare information systems, IS education, and technology-mediated learning. Dr. LeRouge has served in consulting, training, controller, and analyst roles in the software, healthcare, public accounting, and petrochemical industries. She has published research articles in International Journal of Human Computer Studies, Journal of Informatics and Education Research, Journal of Computer Information Systems, Communications of the AIS and International Journal of Healthcare Technology and Management as well as edited chapters in research-based books. Dr. LeRouge has a Ph.D. in information systems from the University of South Florida and a M.Sc. in accounting from the University of New Orleans.

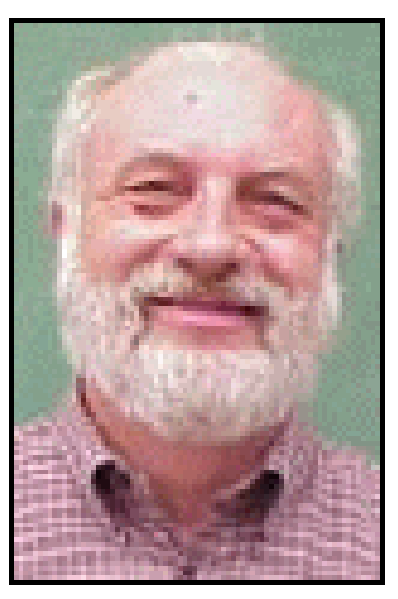

Ken Trimmer is an Associate Professor of Computer Information Systems at Idaho State University. His current research focuses on teams, healthcare informatics issues, systems development, information assurance, technology-mediated learning, and pedagogical cases. He has published research articles in Journal of Computer Information Systems, Computer Personnel, Journal of Information Systems Education, Journal of Management in Medicine, Ethics and Critical Thinking Journal, and Research in Healthcare Financial Management as well as edited chapters in research-based books. He has co-edited a special edition on Information Assurance and Security in The Journal of Organizational and End User Computing. Dr. Trimmer has a Ph.D. in Information Systems from the University of South Florida, a Master of Accounting from Washington State University, and an MBA from Western Carolina University. 